\title{
CONFLUÊNCIAS DE CAMPOS DE SABER NA ANÁLISE DE RITUAIS NA PRODUÇÃO DO SUJEITO EDUCADO
}

\author{
Rosângela Tenório de Carvalho \\ Universidade Federal de Pernambuco (UFPE), Recife, Pernambuco, \\ Brasil
}

\begin{abstract}
ResUMo: O artigo tem como objeto a confluência analítica de estudos sobre rituais e performatividade na antropologia contemporânea de Stanley Tambiah e na arqueogenealogia de Michel Foucault. O objetivo é argumentar em defesa de uma correlação funcional entre esses dois campos de saber para a análise de práticas discursivas no campo educacional que operam com seus rituais na produção do sujeito educado. Acercamo-nos das teorizações desses discursos no modo de tratar rituais e destacamos como confluência no tratamento do ritual: a soberania do empírico como abordagem analítica, tratado como práticas discursivas históricas no caso de Michel Foucault e como práticas culturais no caso de Tambiah; o reconhecimento do ritual traduzido como ação performática.
\end{abstract}

Palavras-chave: Rituais. Performatividade. Sujeito da educação. Antropologia contemporânea.

INTRODUÇÃO

A análise dos rituais na perspectiva da antropologia social contemporânea de Stanley Tambiah associada à análise do discurso de Michel Foucault - uma confluência analítica para o estudo de rituais da escolarização - é o objeto deste artigo. Argumentamos ser possível estabelecer entre os dois 
discursos uma correlação funcional e produtiva para a análise de práticas discursivas que operam no campo educacional com seus rituais na produção do sujeito educado. Temos nos interessado em analisar processos educativos de subjetivação dos indivíduos, com foco na problematização de práticas de subalternidade e de resistência, por se constituírem como contraponto às práticas que colocam o outro numa relação de alteridade em condições subalternas.

Defendemos a possibilidade dessa confluência a partir de um desenho teórico e metodológico inspirado em um mapa analítico "arlequinal". O uso do termo arlequinal é uma forma de, parodiando Mário de Andrade, evocar regularidades em campos de saber com significativas oposições intrínsecas. Nesse sentido, nos aproximamos do campo dos Estudos Culturais, reconhecido como"[...] uma espécie de processo, uma alquimia para produzir conhecimento útil sobre o amplo domínio da cultura humana" (NELSON; TREICHLER; GROSSBERG, 1995, p. 9). Nesse campo, proliferou o importante debate sobre a cultura como prática de significação, no qual há uma interpelação sobre o que a cultura realiza, inclusive, o que ela realiza nos contextos das pedagogias com os sujeitos da educação. Essa, segundo nosso olhar, é a grande contribuição dos Estudos Culturais.

Assim, associamo-nos aos Estudos Culturais por reconhecermos em seus discursos modos de problematizar, na atualidade, a própria relação que construímos no modo de pensar o conhecimento, os fundamentos, as metodologias. Interessa realçar modos de pensar que observem o caráter provisório dos "jogos de verdade" que estão na base das nossas relações com o conhecimento educacional. Nesse sentido, elegemos um caminho que trata de problematizações epistemológicas no pensamento contemporâneo e seus efeitos nas narrativas clássicas do campo educacional.

Tais problematizações estão enredadas no debate sobre o projeto humanista de formação do homo humanus, objeto por excelência do campo educacional. Há, na atualidade, uma movimentação intelectual em torno de questões relacionadas à produção do sujeito humano tendo como objeto de discussão discursos sobre o esgotamento do humanismo nacional-burguês com sua arte de narrativas para construção do sujeito, ou seja, a educação 
como autoformação da espécie (SLOTERDIJK, 2000); questionamentos sobre o conflito político entre a animalidade e a humanidade do homem, conflito que governa todos os outros conflitos apontados por Agamben (2013). Questões que não serão abordadas neste artigo, mas que estão imbricadas com a problemática educacional na atualidade, e de forma mais centrada, nas práticas de formação dos sujeitos aqui tratados pelo nosso foco no ritual como uma das práticas discursivas performáticas.

Interessam-nos não apenas os rituais como práticas relacionadas ao sagrado, ao religioso e à magia, em seu significado dado na antropologia clássica, mas também os rituais cotidianos, rituais profanos, como os microrrituais de passagem para escola (RIVIÈRE, 1996). Os rituais motivam nosso estudo principalmente pela função protetora do "nosso eu profundo" e por permitirem "entrar em contato harmonioso com nosso próximo [...], pois eles nos lembram que somos humanos somente porque outros seres humanos nos constituem como tais" (CHARAUDEAU; MAINGUENEAU, 2004, p. 440).

Nessas perspectivas, o ritual é percebido como uma prática que está associada à submissão de regras preexistentes e, embora pobre em conteúdo informacional, é rico em significação relacional. Destacamos também as suas principais funções, conforme os estudos de Charaudeau e Maingueneau (2004): reparadoras, confirmadoras, pacificadoras, reguladoras e estabilizadoras. A nosso ver, essas funções do ritual estão implicadas com o controle das experiências de formação dos indivíduos. Tais experiências como formas de subjetivação e de dessubjetivação são entendidas como uma correlação em uma cultura, entre domínios de saber (disciplinas), tipos de normatividade (rituais de transmissão - pedagogia) e formas de subjetividade (experiências de si). Nesse sentido, a noção de experiência engloba tanto a percepção do professor/a como o conhecimento dos rituais da formação (CASTRO, 2009).

É nesse cenário discursivo que propomos pensar a possibilidade de confluência entre a visão de Foucault sobre rituais e práticas de disciplinarmento com os estudos antropológicos sobre rituais e performatividades de Tambiah, em seus aspectos mais amplos. Lembramos que o foco da análise é o modo de problematização dos rituais. 


\section{Ritual e modos de subjetivação em Michel Foucault}

Foucault, com sua arqueogenealogia, pretende tecer uma crítica à própria ideia de racionalidade e nessa direção problematiza a questão normativa da verdade e o estabelecimento de uma ordem temporal de recorrências a partir da racionalidade científica. Desenvolve, assim, um modo analítico no qual, segundo Veyne (1995), opera na descrição do que se faz; julga as pessoas por seus atos e não por suas ideologias ou a partir de grandes noções eternas (os governados, o Estado, a liberdade, a essência política); limita os eternos fantasmas que a linguagem suscita em nós; inverte os termos do enunciado. Argumenta Veyne (1995, p. 249), inspirado em Foucault, que: "nossa prática determina esses objetos. Portanto, partamos, antes, dessa própria prática, de tal modo que o objeto ao qual ela se aplique seja o que realmente ela é [...] a relação determina o objeto, e só este o que é determinado".

Os interesses de Foucault seriam as relações entre práticas discursivas e práticas sociais e os efeitos de verdade produzidos pelo discurso, diz Sarfati (2010, p. 115). Sarfati sintetiza a contribuição metodológica de Foucault em quatro aspectos: um campo comum de objetos; um tipo definido e normativo de enunciação ou modalidade enunciativa; um sistema de conceitos permanentes; a permanência de uma temática identificada com as estratégias ou um campo específico.

É preciso destacar outros aspectos no modo de operar na pesquisa em Foucault, a exemplo do modo de reapropriação de enunciados do passado para compreender as condições de produção de práticas discursivas no campo da educação atual (FOUCAULT, 1996); o modo como encara a pesquisa em sua relação com o ensino como um processo ético, tal como o faz ao dizer em seu texto Em Defesa da Sociedade:

já que se é pago para fazer pesquisa, o que pode controlar a pesquisa que se faz? De que maneira se pode manter a par aqueles que podem se interessar por ela e aqueles que têm alguns motivos de estar ligados a essa pesquisa? Como é que se pode fazer, senão finalmente pelo ensino, isto é, pela declaração pública, a prestação de contas pública e relativamente regular, do trabalho que se está fazendo? (FOUCAULT, 2002, p. 3). 
Ou o modo como esclarece o percurso que vão tomar, em suas pesquisas, os princípios gerais, "as instruções imperativas ou as precauções do método que quis tomar" (FOUCAULT, 2002, p. 29). O modo como quer dar esclarecimentos como um modo de na pesquisa fazer a pesquisa. $O$ modo como se interessa pela intensidade e constância das relações de poder e não por elas em si. O tratamento que dá aos textos como discurso; e o modo como apresenta a problemática da pesquisa, ou seja, o seu problema teórico, com um modo de construir perguntas de forma singular; e a apresentação do processo da pesquisa, o caminho, os descaminhos, o que prolifera, o que abandona, o que refaz ao anunciar mudanças na apresentação do seu estudo sobre a análise da governamentalidade liberal, pulando dois séculos, XVIII e XIX, e indo direto ao século XX, reservando-se "o direito de fazer mudanças - porque, como vocês sabem, sou como o lagostim, ando de lado..." (FOUCAULT, 2008, p. 107). E, particularmente, o modo de fazer pensar. Foucault faz a pergunta pensamento. Joga com as palavras como diz: "suponhamos que a loucura não exista. Qual é, por conseguinte, a história que podemos fazer desses diferentes acontecimentos, dessas diferentes práticas que, aparentemente, se pautam por esse suposto algo que é a loucura?" (FOUCAULT, 2008, p. 5).

É preciso dizer que o modo de problematizar está implicado com uma conceitualização poderosa, com capacidade, potência nos recursos analíticos. Nesse sentido, destaco a problematização que Foucault faz da cultura - concordo com Eduardo Lourenço quando diz, no prefácio das $\mathrm{Pa}$ lavras e as Coisas, versão portuguesa do livro de Foucault, que o filósofo é o problematizador da Cultura, tal como Marx foi o problematizador da Classe Social (2002). Um analista da cultura, entendendo-se cultura ao seu olhar "não apenas produção de obras de arte, mas, igualmente instituições políticas, forma de vida social, proibições e imposições diversas" (FOUCAULT, 1996, p. 56). Dentro dessa conceitualização, tenho destacado o ritual disciplinar na constituição de subjetividades multidimensionais. Contudo, trabalhar com essa conceitualização exige, a nosso ver, a convergência com modos de problematização e de uso de conceitualizações desenvolvidas por outros campos e autores, a exemplo da confluência com os estudos de Tambiah. 
Para associar o trabalho de Foucault com o ritual, elegemos alguns de seus textos nos quais o autor realça o seu papel na produtividade do discurso sobre os sujeitos. Com o texto A ordem do discurso, Foucault (1999) chamou a atenção para a relação imanente entre processos educativos e práticas ritualísticas. Com efeito, em sua aula inaugural do Collège de France, ele trata da temática do ritual, seja para dizer das formas ritualizadas que cercam começos solenes, seja para abordar o controle do que se pode dizer pelo ritual da circunstância; rememora como os gregos do século VI proferiam o discurso verdadeiro no cenário do ritual requerido; indica como chegou um momento em que o discurso verdadeiro dependia pouco do que era ou dizia e como a verdade se "deslocou do ato ritualizado de enunciação, eficaz e justo, para o próprio enunciado: para o seu sentido, a sua forma, o seu objecto, a sua relação à referência" (FOUCAULT, 1999, p. 15).

Com Foucault, aprendemos que os diferentes discursos, como os religiosos, jurídicos, terapêuticos, políticos, dependem de um ritual que orienta para "os sujeitos falantes, ao mesmo tempo, propriedades singulares e papéis convenientes" (FOUCAULT, 1999, p. 12). Ou seja, esses discursos não são dissociáveis do exercício de um ritual que determina para os sujeitos falantes, ao mesmo tempo, propriedades singulares e papéis convenientes. O ritual, portanto, faz parte de sistemas complexos de restrição - uma forma superficial e visível desses sistemas. Diz Foucault que:

o ritual define a qualificação que devem possuir os indivíduos que falam (e que, no jogo do diálogo, na interrogação, na recitação, devem ocupar determinada posição e formular determinado tipo de enunciados); define os gestos, os comportamentos, as circunstâncias e todo o conjunto de sinais que devem acompanhar o discurso; o ritual fixa, por fim, a eficácia, suposta ou imposta, das palavras, o seu efeito sobre aqueles a quem elas se dirigem, os limites do seu valor constrangedor. (FOUCAULT, 1999, p. 12).

No que se refere à educação, e mais especificamente, aos sistemas de ensino, indaga Foucault:

O que é, no fim de contas, um sistema de ensino senão uma ritualização da fala, senão uma qualificação e uma fixação dos papéis dos sujeitos falantes; senão a constituição de um grupo doutrinal, por difuso que seja; senão uma distribuição e uma apropriação do discurso com os seus poderes e os seus 
saberes? O que é a "escrita" (a dos "escritores") senão um sistema de sujeição semelhante, que assume talvez formas um pouco diferentes, mas em que as grandes decomposições são análogas? Será que o sistema jurídico, o sistema institucional da medicina, também eles, pelo menos em alguns dos seus aspectos, não são sistemas semelhantes de sujeição do discurso? (FOUCAULT, 1999, p. 14).

Foucault mostra que o ritual atua no contexto do discurso como um procedimento de exclusão interna do discurso, a exemplo de "coleções ritualizadas de discursos que se recitam em circunstâncias determinadas; coisas ditas uma vez e que são preservadas, porque suspeitamos que nelas haja algo como um segredo ou uma riqueza" (FOUCAULT, 1999, p. 16).

Para Foucault, é por meio de rituais que se dão os jogos de verdade (conjunto de regras de produção da verdade), o olhar normalizador e a vigilância. Essas práticas têm na ação pedagógica um lugar central pelo que é próprio da prática da pedagogia - a ação de transmissão de enunciados e de práticas intencionais ou não da formação dos indivíduos.

O processo de produção dos indivíduos como efeito da relação pedagógica constitui uma das temáticas mais complexas e cruciais do campo educacional. Estudos no campo educacional, associados à produção intelectual de Michel Foucault, observam como diversos e diferentes dispositivos estão implicados nesse processo, a exemplo da pedagogia e do currículo. Tais estudos no campo da educação articulam a relação entre currículo, cultura e subjetividades, como, por exemplo, os escritos de Silva (1996), Corazza (2001), Costa, (2000), Larrosa (1994).

Nesses estudos, são nomeados os currículos e outros regulamentos, práticas didáticas, práticas de avaliação como ações pedagógicas que, para além de sua ação na aprendizagem, na aquisição da cultura, operam por meio de ações que hierarquizam, subordinam, legitimam ou desqualificam os sujeitos. Observa-se o realce dado a aparatos discursivos e linguísticos na produção do sujeito moderno, ao se dar mais visibilidade a tecnologias de classificação e divisão na produção dos sujeitos, tal como defende Larrosa (1994, p. 52).

Importa dizer que, em Foucault, os processos de subjetivação do sujeito são vistos como modos de subjetivação, modos de objetivação do in- 
divíduo (CASTRO, 2009, p. 408), práticas de constituição desse sujeito educado (no caso da educação). Tais práticas são explicadas melhor com o conceito de governamentalidade desenvolvido por Foucault: "maneira como se conduz a conduta dos homens", (FOUCAULT, 2008, p. 258). Governamentalidade, nesse sentido, remete à arte de governar, arte que opera pelo encontro entre as técnicas de poder que estão a determinar a conduta dos indivíduos e as técnicas de si, que permitem aos indivíduos efetuarem, eles mesmos, ou com a ajuda dos outros, operações sobre os seus modos de ser.

Foucault, ao tratar das técnicas de si, lembra que, nos Discours sacrés, escritos do século Il, a obra de Aelius Aristides apresenta dois tipos de discurso sobre os sonhos. Um sobre o relato detalhado das atividades cotidianas e outro de conotação ritual dos louvores dirigidos aos deuses. Este último é que tem a função de matriz daqueles discursos e a função curativa dos deuses, isto é, o poder do discurso ritualístico.

Entre as técnicas de si de tradição cristã, destaca o ritual - exomologêsis - ritual pelo qual um indivíduo se reconhecia como pecador e como penitente. Distingue a tradição estoica da tradição cristã. Diz Foucault:

na tradição estoica, o exame de si, o julgamento e a disciplina franqueiam o acesso ao conhecimento de si ao utilizar a memória, quer dizer, a memorização das regras, para fazer aparecer, em alto relevo, a verdade do indivíduo sobre ele mesmo. No exomologêsis, é por uma ruptura e uma dissociação violentas que o penitente faz aparecer a verdade sobre ele mesmo. É importante ressaltar que esse exomologêsis não é verbal. É simbólico, ritual e teatral. (FOUCAULT, 2004, v. 5, p. 100).

O conhecimento dessas técnicas, segundo Foucault, justifica a análise da genealogia do sujeito na civilização ocidental, pois não há habilidade que possa ser adquirida fora do exercício, fora dos rituais, inclusive a arte de viver não prescinde de uma askêsis que deve ser cumprida como um treino de si por si mesmo (FOUCAULT, 2004, v. 5, p. 146).

No que se refere à educação, pode-se dizer que os modos de subjetivação estão mais associados aos artefatos em seus rituais do que ao conteúdo educacional. Os modos de subjetivação estariam associados aos artefatos pelo que eles conduzem de ritual, de formalização pelo que suscitam de revelação de si, avaliação de si e rememoração de si. 


\section{Ritual e PeRFormatividade na Perspectiva de Stanley Tambiah}

A temática do ritual esteve presente no trabalho de Tambiah desde o início de sua formação como pesquisador, tal como revela em entrevista a Peirano em 1996 (TAMBIAH, 1997). Nessa entrevista, Tambiah diz que se tornou antropólogo em meados dos anos 1950, quando iniciou um trabalho de campo com o economista e estatístico N. K. Sarkar e realizou um survey ao qual agregou um trabalho de campo sobre estrutura de parentesco e organização social. O seu encontro com o antropólogo Edmund Leach foi determinante, pois, além de considerar Tambiah um antropólogo nato, Leach auxiliou na publicação do seu trabalho de campo em Man (JRAl). Diz Tambiah que, naquele período, tinha interesse pela

observação participante, conversar com as pessoas, observar rituais, e ver situações no seu contexto, tudo aquilo que você não pode fazer em um survey, no qual você faz perguntas em série sem conhecer ou mapear em profundidade suas inter-relações. (TAMBIAH, 1997, p. 200).

Para Peirano, a abordagem de Tambiah sobre ritual pode ser comparada "com o que Jakobson fez com a afasia, Lévi-Strauss com o totemismo, Freud com os sonhos..." (TAMBIAH, 1997, p. 208). A autora realça como Tambiah atua com o ritual transformando o que era um objeto empírico em uma abordagem analítica.

O ritual em Tambiah está implicado com uma ação performática. Esse modo de desenvolver essa abordagem está relacionado ao seu encontro intelectual com a produção de Austin e como incorporou suas ideias apresentadas no texto Form and Meaning of Magical Acts, tal como revela Peirano. Mesmo em desacordo com Leach, diz que "estava convencido de que a ideia de Austin sobre as locuções performativas era importante" (TAMBIAH, 1997, p. 210).

Com efeito, na teoria da linguagem, desde Austin, performativo passou a ser usado com um sentido preciso, produtivo analiticamente. Inclusive outros autores, além de Tambiah, desenvolveram esse conceito de Austin no contexto dos seus estudos, a exemplo de Derrida (1971), ao argumentar que o que caracteriza os atos de linguagem é sua "citacionalidade": a possibilidade de que eles sejam iterados, citados ou repetidos independentemente da presença de quem 
originalmente os emitiu ou recebeu. Butler (2003) combina as contribuições desses dois autores para defender que a identidade de gênero e a identidade sexual são produzidas por meio de repetidos enunciados performativos. Jean-François Lyotard, em O pós-moderno, defende que, "em contraste com a era anterior, em que as narrativas científicas tinham sua legitimidade julgada de acordo com critérios de verdade, na era pós-moderna elas são julgadas de acordo com critérios de performatividade" (SILVA, 2000, p. 90-91).

Lyotard (1988) opera com essa conceitualização desenvolvida por Austin, e, nesse sentido, ressalta como as mensagens são dotadas de formas e efeitos diferentes conforme seu tom denotativo, prescritivo, avaliativo, performativo. Exemplifica, ao examinar narrativas populares:

A forma narrativa obedece a um ritmo, é a síntese de um metro que marca o tempo em períodos regulares e com um acento que modifica o comprimento ou a amplitude de algumas dentre elas. Esta propriedade vibratória e musical torna-se evidente na execução ritual de alguns contos cashinahua: transmitidos nestas condições iniciáticas, de uma forma absolutamente fixa, numa linguagem que torna obscuros os desregramentos lexicais e sintáticos que se lhe inflige, são cantados em intermináveis melopeias. Estranho saber, dir-se-á, que nem ao menos se faz compreender pelos jovens a quem se dirige! (LYOTARD, 1988, p. 40).

Outras ideias associadas a autores importantes no campo da lingugem, como Charles Sanders Peirce, do campo da semiótica, e Ramon Jakobson, do campo da análise estrutural da linguagem, são utilizadas por Tambiah em seus estudos sobre rituais, a exemplo das obras: Rituali e Cultura e The Magical Power of Words, entre outras. Nessas obras, o discurso de Tambiah evidencia a relação entre ritual e linguagem, isto é, o funcionamento da linguagem não em termos denotativos, mas performativos. Nessa perspectiva, Tambiah (1995), vê o ritual como um sistema construído culturalmente e como um sistema comunicativo em contextos específicos. Com Tambiah, somos levados a tratar o ritual considerando a sua proposição de unir semântica e pragmática. Isto é possível porque Tambiah funde o modelo linguístico estrutural de Saussure e Lévi-Strauss com o conceito de discurso como ato performático de Austin e o conceito de signo na perspectiva semiótica de Peirce (LEONINE, 1995). 
Rodrigues (2014) faz uma síntese dessas influências a partir de sua interpretação do texto Culture, Thought and Action Social de Tambiah no modo de apresentar três sentidos do ritual:

O primeiro é retirado de J. L. Austin (1962), segundo o qual "dizer" é nomear uma coisa com palavras. Neste sentido, poderíamos destacar o"sim" dito no casamento, ou quando o padre diz "eu te batizo". Logo, se o dito é feito, é também ação social. O segundo sentido apresentado por Tambiah refere-se à ação performativa como a repetição e encenação de um ritual que é expresso em uma multiplicidade de meios, implicando em diversas modalidades sensoriais por meio das quais os participantes vivem o evento intensamente, como, por exemplo, o carnaval ou mesmo uma partida de futebol. Um último sentido refere-se a valores "indexicais", um conceito adaptado de Peirce, que são transferidos para os atores e inferidos pelos mesmos, conferindo-lhes deste modo prestígio, legitimidade, autoridade, poder e outras formas de capital simbólico. (RODRIGUES, 2014, 192).

Segundo Silva (2000), o conceito de performatividade em Austin é desenvolvido quando o autor faz a distinção entre enunciados constatativos (ou descritivos) e enunciados performativos. Para Austin, os enunciados constatativos também podem, sob certas circunstâncias, atuar como performativos: uma declaração de fato pode acabar produzindo o "fato" que supostamente apenas descreve.

O registro de Tambiah sobre essa questão o leva a apresentar uma abordagem do ritual do ponto de vista performativo. Por ritual entende, então, que

II rituale è un sistema di comunicazione simbolica constrito culturalmente. 'constituito da sequenze di parole e atti, strutturati e ordinati e spesso espressi com molteplice mezzi, il cui contenuto e la cui disposizione sono caratterizzati in vario grado da formalismo (convenzionalità), stereotipia (rigidità) condensazione (fusione) e ridondanza (ripetizione). Nelle sue caratteristiche constituive, I'azione rituale è performativo, in quiesti tre sensi: nel senso austiniano de performativo, incui dire qualcosa è anche fare qualcosa, in quanto atto convenzionale; nel senso, abbastanza diverso, di comunicazione, grazie al quali e partecipanti sperimentano intensamente l'evento; e nel senso del valori inicati - ricavo questo concetto de Peirce - essendo connesso com (e inferito da) gli attori durante la rappresentazione. (TAMBIAH, 1995, p. 130-131). ${ }^{11}$

11 O ritual é um sistema de comunicação simbólica construído culturalmente. É constituído de sequências de palavras e atos, estruturado, ordenado e em geral expresso por múltiplos meios cujos conteúdo 
O que faz Tambiah é romper com a tradição saussuriana de enfatizar a distinção entre langue e parole. Tambiah passa a enfatizar "que o ato mágico tem significados predicativos e referenciais, mas é também performativo" (PEIRANO, 2002, p. 25). Peirano (2002) faz uma interessante síntese do modo analítico do ritual de Tambiah:

o ritual esclarece mecanismos fundamentais do repertório social. Em outras palavras: falas e ritos - esses fenômenos que podem ser recortados na sequência dos atos sociais - são bons para revelar processos também existentes no dia a dia e, até mesmo, para se examinar, detectar e confrontar as estruturas elementares da vida social. (PEIRANO, 2002, p. 29).

Na ação ritualística, o conteúdo cultural é radicado em uma cosmologia, ou seja, no corpo de concepções que elenca e classifica os fenômenos que compõem o universo como um todo, ordenado, assim, como as normas e processos que o governam.

Nessa perspectiva, a ação ritualística tem sua dimensão formal e dimensão contextual. Verificar essas dimensões potencializa a identificação da estrutura, da ordem, da cosmologia nos discursos educativos que estão implicados nos processos de subjetivação dos indivíduos.

\section{CONFLUÊNCIAS}

Na perspectiva de encerrar este artigo, fazemos agora uma síntese das confluências entre o modo de analisar o ritual no campo da antropologia social contemporânea com Staley Tambiah e as práticas analíticas de análise do ritual em Michel Foucault. Tal confluência é possível se considerarmos pelo menos duas razões: a primeira refere-se à consideração da soberania do campo empírico, no caso de Michel Foucault, para as práticas discursivas históricas, situadas, e o reconhecimento por Tambiah de que o objeto empírico só pode ser compreendido a partir de uma abordagem analítica. A segunda

e arranjo são caracterizados por graus variados de formalidade (convencionalismo), estereotipia (rigidez), condensação (fusão) e redundância (repetição). Nos seus traços constitutivos, a ação ritual é performativa em três sentidos: no sentido austiniano de performativo no qual dizer alguma coisa é também fazer alguma coisa como um ato formal; no sentido bastante diverso, o das comunicações, graças aos quais os participantes experimentam intensamente o evento; e, no sentido dos valores indicados - tomo esse conceito de Peirce - conectados com valores inferidos pelos atores durante a performance. (Tradução nossa). 
trata do reconhecimento da linguagem, do discurso, como ação na produção daquilo que fala, nomeia, enuncia, traduzida como ação performática.

Deve-se ressaltar a existência de uma tensão na relação entre o modo de conhecer da antropologia e o modo de conhecer dos estudos culturais, dos estudos pós-estruturalistas, pós-modernos, com os quais o trabalho de Michel Foucault estabelece uma interlocução. Contudo, pretende-se com este artigo fazer uma ponte entre essas referências para dar visibilidade à possível confluência entre os modos de tratar o ritual e indicar sua adequação a análises que tratem de processos de subjetivação dos indivíduos. Optamos por nos ligarmos ao modo como Tambiah (1997) vê essa tensão:

Minha visão particular é que os antropólogos devem ponderar essas considerações, digerir as críticas, e então prosseguir com seu trabalho de campo e escrita antropológicos, que devem incorporar criativamente as considerações pós-modernas. Por outro lado, devem admitir e assumir que diferentes formas de vida podem ser documentadas e que as circunstâncias e contextos de coleta de dados e representação autoral são parte do texto. Seria um erro dissolver a antropologia como disciplina ou reduzi-la a confrontos de egos altamente personalizados, que revelam mais as preocupações neuróticas de um outro invasor do que a riqueza das formas de vida das outras sociedades, cujo conhecimento vai sempre aprofundar e iluminar nossas próprias vidas e sociedades. (TAMBIAH, 1997, p. 218).

Ao tematizar dessa forma a autoria, Tambiah parece incorporar de forma produtiva o papel do autor, daquele que imagina sua existência fora da função do autor trabalhada nos estudos analíticos de Foucault, ou seja, a posição que pode ocupar o indivíduo para ser sujeito da função ator, já que o"sujeito aqui é uma função vazia a ser preenchida por indivíduos diferentes" (FOUCAULT, 1995, p. 109).

CONFLUENCE OF FIELDS OF KNOWLEDGE IN THE ANALYSIS OF RITUALS DURING THE PRODUCTION OF AN EDUCATED PERSON

ABSTRACT: The goal of this article is the analytical confluence of ritual studies and performativity in the contemporary anthropology of Stanley Tambiah and in the archaeogenealogy of Michel Foucault. It aims to argue in favor of a functional correlation between two fields of knowledge for the analysis of discursive practices in education that are present during the production of an educated person. Based on the theoretical aspects of these discourses in the way of dealing with rituals, we highlight 
the confluence in the treatment gave to the ritual: the sovereignty of the empirical and analytical approach, treated as historical discursive practices in the case of Michel Foucault and as cultural practices in the case of Tambiah; the recognition of the ritual translated as performative action.

KeYwords: Rituals. Performativity. Subject of education. Contemporary Anthropology.

\section{CONFLUENCIAS ENTRE CAMPOS DE SABER EN EL ANÁLISIS DE RITUALES EN LA PRODUCCIÓN DEL SUJETO EDUCADO}

RESUMEN: El artículo tiene por objeto abordar la confluencia analítica de estudios sobre rituales y la performatividad en la antropología contemporánea de Stanley Tambiah y en la arqueo genealogía de Michel Foucault. El objetivo es argumentar a favor de una correlación funcional entre estos dos campos del conocimiento para el análisis de prácticas discursivas en el campo de la educación, que operan con sus rituales en la producción del sujeto educado. Nos acercamos a las teorizaciones de esos discursos en su modo de tratar rituales y resaltamos cómo la confluencia en el trato del ritual: la soberanía del empírico como abordaje analítico, entendido como prácticas discursivas históricas en el caso de Michel Foucault y cómo prácticas culturales en el caso de Tambiah; el reconocimiento del ritual traducido como acción performática.

Palabras Clave: Rituales. Performatividad. Sujeto de la educación. Antropología contemporánea.

\section{REFERÊNCIAS}

AGAMBEN, G. O Aberto. O Homem e o Animal. Rio de Janeiro: Civilização Brasileira, 2013.

BUTLER, J. Problemas de gênero: feminismo e subversão da identidade. Rio de Janeiro: Civilização Brasileira, 2003

CASTRO, E. Vocabulário Foucault: Um percurso pelos seus temas, conceitos e autores. Tradução Ingrid Müller Xavier. Belo Horizonte: Autêntica, 2009.

CHARAUDEAU, P.; MAINGUENEAU, D. Dicionário de análise de discurso. São Paulo: Contexto, 2004.

CORAZZA, S. M. O que quer um currículo? Pesquisas pós-críticas em educação. Petrópolis: Vozes, 2001. 
COSTA, M. V. (Org.). Estudos Culturais em educação: mídia, arquitetura, brinquedo, biologia, literatura, cinema. Porto Alegre: Ed. Universidade/UFRGS, 2000.

DERRIDA, J. A Escritura e a Diferença. São Paulo: Perspectiva, 1971.

FOUCAULT, M. A arqueologia do saber. Tradução de Luiz Felipe Baeta Neves. 4. ed. Rio de Janeiro: Forense Universitária, 1995.

A Escrita de Si. In: MOTA, Manuel Barros da (Org.). Michel Foucault, Ética, Sexualidade, Política. Rio de Janeiro: Forense Universitária, 2004. p. 144.162.

. A Ordem do Discurso. São Paulo: Loyola, 1999.

. As palavras e as coisas: uma arqueologia das ciências humanas. 2. ed. Lisboa: Edições 70, 2014.

Dits et écrits. Paris: Gallimard, 1994, Vol. IV, p. 783-813. Traduzido por Karla Neves e Wanderson Flor do nascimento. Espaço Michel Foucault. Disponível em: <www.filoesco.unb.br/foucault>. Acesso em: 2 dez. 2004.

Em defesa da sociedade: Curso no Collège de France (1975-1976). Tradução Maria Ermantina Galvão. São Paulo: Martins Fontes, 2002.

As palavras e as coisas. Lisboa: Portugalia, 1996.

Nascimento da Biopolítica: curso dado no Collège de France (1878-1979)/ Michel Foucault; edição estabelecida por Michael Senellart; sob a direção de François Ewald e Alesandro Fontana. São Paulo: Martins Fontes, 2008. (Coleção tópicos).

LARROSA, J. Tecnologias do Eu e Educação. In: SILVA, Tomaz Tadeu (Org.). O Sujeito da Educação. Petrópolis, RJ: Vozes, 1994. p. 35-86.

LEONINE, L. Prefazione all'edizione italiana. In:TAMBIAH, S. J. Rituali e cultura. Traduzione di Daniela Garavini. Bologna: Ediciones Italiana, 1995. p. 7-16.

LOURENÇO, E. Michel Foucault ou o Fim do Humanismo. In: FOUCAULT, Michel. As Palavras e As Coisas. Lisboa: Edições 70, 2002. p. 9-20.

LYOTARD, J. F. O Pós-Moderno. 3. ed. Tradução Ricardo Corrêa Barbosa. Rio de Janeiro: José Olympio, 1988.

NELSON, C.; TREICHLER, A.; GROSSBERG, L. Estudos Culturais: Uma introdução. In: SILVA, T. T. (Org.). Alienígenas na sala de Aula. Petrópolis, RJ: Vozes, 1995. p. 7-34.

PEIRANO, M. A análise antropológica de rituais. In: (Org.). O dito e o feito: ensaios de antropologia dos rituais. Rio de Janeiro: Relume Dumará, Núcleo de Antropologia da Política/UFRJ, 2002. p. 17-40

. Rituais, ontem e hoje. Rio de Janeiro: Jorge Zahar, 2003.

RIVIÈRE, C. Os ritos profanos. Petrópolis, RJ: Vozes. 1996. 
RODRIGUES, R. Ritual em Tambiah: trajetória, conceitos e reflexões. Revista Brasileira de História das Religiões, Ano 7, n. 20, p. 187-197, set. 2014.

SARFATI, G. É. Princípios da análise do discurso. Tradução Marcos Bagno. 1. ed. São Paulo: Ática, 2010.

SILVA, T. T. Identidades Terminais. Petrópolis, RJ: Vozes, 1996.

2000 .

Teoria cultural e educação: um vocabulário crítico. Belo Horizonte: Autêntica,

SLOTERDIJK, Peter. Regras para o parque humano: Uma resposta à carta de Heidegger sobre o humanismo. São Paulo: Estação Liberdade, 2000.

TAMBIAH, S. J. Continuidade, integração e horizontes em expansão. Entrevista concedida a Mariza Peirano. MANA, v. 3, n. 2, p. 199-219, out. 1997.

. Rituali e cultura. Bologna: II Mulino, 1995.

.The Magical Power of Words. Man, New Series, v. 3, n. 2, p. 175-208, jun. 1968.

VEYNE, P. Como se escreve a história: Foucault revoluciona a história. Brasília, DF: UnB, 1995.

ROSÂNGELA TENÓRIO DE CARVALHO: Doutora em Ciências da Educação pela Universidade do Porto, Portugal. Atualmente é professora associada da Universidade Federal de Pernambuco (UFPE). Suas mais recentes pesquisas têm privilegiado a relação entre cultura e educação, trabalhando especialmente nos campos teóricos do discurso foucaultiano e dos estudos culturais. Dedica-se em sua pesquisa as questões relacionadas aos modos de subjetivação por meio de praticas curriculares e rituais nas relações de gênero, raça e etnia.

E-mail: rosangelatc@smail.com 